\title{
ErbB3 drives mammary epithelial survival and differentiation during pregnancy and lactation
}

Michelle M. Williams', David B. Vaught ${ }^{1}$, Meghan Morrison-Joly ${ }^{1}$, Donna J. Hicks' ${ }^{1}$ Violeta Sanchez ${ }^{2}$, Philip Owens ${ }^{1}$, Bushra Rahman ${ }^{1}$, David L. Elion', Justin M. Balko² and Rebecca S. Cook ${ }^{1 *}$

\begin{abstract}
Background: During pregnancy, as the mammary gland prepares for synthesis and delivery of milk to newborns, a luminal mammary epithelial cell (MEC) subpopulation proliferates rapidly in response to systemic hormonal cues that activate STAT5A. While the receptor tyrosine kinase ErbB4 is required for STAT5A activation in MECs during pregnancy, it is unclear how ErbB3, a heterodimeric partner of ErbB4 and activator of phosphatidyl inositol-3 kinase (PI3K) signaling, contributes to lactogenic expansion of the mammary gland.

Methods: We assessed mRNA expression levels by expression microarray of mouse mammary glands harvested throughout pregnancy and lactation. To study the role of ErbB3 in mammary gland lactogenesis, we used transgenic mice expressing WAP-driven Cre recombinase to generate a mouse model in which conditional ErbB3 ablation occurred specifically in alveolar mammary epithelial cells (aMECs).

Results: Profiling of RNA from mouse MECs isolated throughout pregnancy revealed robust Erbb3 induction during mid-to-late pregnancy, a time point when aMECs proliferate rapidly and undergo differentiation to support milk production. Litters nursed by ErbB3 ${ }^{K O}$ dams weighed significantly less when compared to litters nursed by ErbB3 ${ }^{W T}$ dams. Further analysis revealed substantially reduced epithelial content, decreased aMEC proliferation, and increased aMEC cell death during late pregnancy. Consistent with the potent ability of ErbB3 to activate cell survival through the PI3K/Akt pathway, we found impaired Akt phosphorylation in ErbB3 ${ }^{K O}$ samples, as well as impaired expression of STAT5A, a master regulator of lactogenesis. Constitutively active Akt rescued cell survival in ErbB3-depleted aMECs, but failed to restore STAT5A expression or activity. Interestingly, defects in growth and survival of ErbB3 ${ }^{K O}$ aMECs as well as Akt phosphorylation, STAT5A activity, and expression of milk-encoding genes observed in ErbB3 ${ }^{K O}$ MECs progressively improved between late pregnancy and lactation day 5. We found a compensatory upregulation of ErbB4 activity in ErbB3 ${ }^{K O}$ mammary glands. Enforced ErbB4 expression alleviated the consequences of ErbB3 ablation in aMECs, while combined ablation of both ErbB3 and ErbB4 exaggerated the phenotype.
\end{abstract}

Conclusions: These studies demonstrate that ErbB3, like ErbB4, enhances lactogenic expansion and differentiation of the mammary gland during pregnancy, through activation of Akt and STAT5A, two targets crucial for lactation.

Keywords: ErbB3, ErbB4, STAT5A, Jak2, Lactation, Mammary gland development, Prolactin, Alveolar mammary epithelial cell, PI3 kinase, Akt

\footnotetext{
* Correspondence: Rebecca.cook@vanderbilt.edu

1Department of Cancer Biology, Vanderbilt University School of Medicine,

2220 Pierce Avenue, Rm 749 Preston Research Building, Nashville, TN 37232,

USA

Full list of author information is available at the end of the article
} 


\section{Background}

The orchestrated development of the mammary gland requires several molecularly controlled, evolutionarily conserved, and temporally distinct processes [1], occurring to a large extent in adolescents and adults of mammalian species. The mammary gland is comprised of several distinct stem cell, progenitor cell, and mature mammary epithelial cell (MEC) subpopulations that each perform a specialized function at distinct developmental stages [2-7]. During pregnancy, as the mammary gland prepares for synthesis and delivery of milk to newborns, an apically located (i.e., luminal) MEC subpopulation proliferates rapidly in response to systemic hormonal cues such as progesterone and prolactin (PRL), as well as locally derived cues such as neuregulin (NRG, also known as heregulin). At parturition, these milk-producing MECs, referred to as alveolar MECs (aMECs), undergo terminal differentiation for milk synthesis and delivery [8]. This entire process is referred to as lactogenesis, a fundamental requirement for the survival of all mammalian species [9-11].

Several studies demonstrated that PRL-mediated milk production requires signaling through a molecular axis involving PRL receptor (PRLR)-mediated activation of the intracellular tyrosine kinase (TK) Janus kinase 2 (Jak2), which phosphorylates the transcription factor signal transducer and activator of transcription 5A (STAT5A), an obligate transactivator of several milk protein-encoding genes, including Csn 2 (the gene encoding $\beta$-casein) $[8,12-16]$. Genetically engineered mouse models (GEMMs) confirmed that the PRL/PRLR/Jak2/STAT5A signaling axis is crucial for lactogenesis [17-19].

Although STAT5A is potently activated by PRLR/JAK2 signaling, STAT5A also forms complexes with other receptors in MECs [20, 21]. Among these is the receptor tyrosine kinase (RTK) ErbB4 [22-24], a member of the epidermal growth factor receptor (EGFR) RTK family, comprised of EGFR, HER2/ErbB2, HER3/ErbB3, and HER4/ErbB4. Interestingly, ErbB4 activity in the mammary gland, specifically in luminal aMECs, peaks during pregnancy and lactation [25], similar to what is seen for STAT5A. Multiple GEMMs of ErbB4 ablation in the mammary epithelium each display reduced expansion of alveolar structures during pregnancy, decreased terminal aMEC differentiation, impaired activation of STAT5A, lactation defects $[20,26,27]$, and phenocopying of the effects of PRL, PRLR, JAK2, or STAT5A loss. Conversely, increased ErbB4 kinase signaling activates STAT5A, even in the absence of pregnancy-related hormones [28], confirming the role of ErbB4 in STAT5A-mediated lactogenesis.

ErbB4 is ligand activated by NRG family members (NRG1-4), and by certain EGF-like family members (heparin-binding EGF (HB-EGF), betacellulin (BTC), and epiregulin). NRG1 expression by alveolar basal/ myoepithelial MECs is induced at mid-gestation in response to p63, a master regulator of transcriptional programs directing cell fate. NRG initiates proliferation of adjacent aMECs through ErbB4/STAT5A activation [23]. Similar to what was seen with ErbB4 loss, mouse models lacking NRG1 $\alpha$ or NRG1 $\beta$ expression [29], NRG bioavailability [23], or HB-EGF bioavailability [30] suffered decreased aMEC expansion during pregnancy. Conversely, NRG1-loaded slow release pellets implanted into mouse mammary glands induced precocious lactogenesis in nonpregnant mice [31]. The NRG ligands also bind to ErbB3, inducing ErbB3 heterodimerization with other EGFR family receptors, and indeed with a growing list of heterologous RTKs [32, 33]. Ligand-activated ErbB3 has been described as lacking intrinsic kinase activity [34], but once phosphorylated by a heterodimeric partner it potently stimulates cell survival signaling [35]. The role of ErbB3 in MEC cell survival is illustrated by distinct models of impaired ErbB3 signaling in the mammary epithelium during puberty, each causing impaired cell survival of ductal MECs and decreased lengthening of mammary duct.

The ability of ErbB3 to enhance cell survival is explained largely in part by its six binding sites for the p85 regulatory subunit of phosphatidyl inositol-3 kinase (PI3K) [24], more than any other RTK. When phosphorylated, ErbB3 interacts with $\mathrm{p} 85$ to promote PI3K activity, which generates the second messenger phosphoinositol- $(3,4,5)$ trisphosphate (PIP3), causing Akt recruitment, Akt phosphorylation (via PDK1 [36] and mTORC2 [37], which also are recruited by PIP3), and Akt kinase activation. Akt sits at the apex of a signaling cascade that supports cell survival, growth, metabolism, and cell cycle progression [38]. Several lines of evidence demonstrate that PI3K/Akt signaling supports lactogenesis of aMECs through cell survival. For example, models in which Akt signaling was impaired caused aMEC apoptosis, decreasing the capacity for lactogenic alveolar expansion during pregnancy, and causing premature mammary gland involution at parturition [39-42], while models of increased PI3K/Akt signaling, for example, through expression of myristoylated Akt1 (Akt ${ }^{\mathrm{myr}}$ ) in the mammary epithelium, delayed the onset of postlactational cell death upon weaning [43-45]. Given that ErbB3 potently activates PI3K/Akt signaling, it is possible that ErbB3 may be required for lactogenic aMEC expansion during pregnancy. However, its role in aMECs is not yet clear, as two mouse models of ErbB3 ablation have produced disparate results. Although lactogenic aMEC expansion during pregnancy occurred normally in embryonic mammary bud transplants from a classical model of ErbB3 ablation to wildtype recipients [46], a knock-in model eliminating each of the ErbB3 p85-PI3K binding motifs within an otherwise 
intact ErbB3 reduced aMEC expansion during pregnancy, causing increased aMEC cell death and accelerated involution [47].

We used a mouse model of ErbB3 ablation specifically from aMECs, finding delayed aMEC expansion due to decreased Akt-dependent survival of cytokeratin 8 (CK8)positive aMECs, and decreased STAT5A-mediated expression of milk-encoding genes. Restoration of Akt signaling rescued survival of ErbB3-depleted aMECs, but did not rescue STAT5A induction or milk protein expression. However, signaling through both Akt and STAT5A were rescued by ErbB4 overexpression. In vivo, compensatory ErbB4 upregulation in ErbB3-deficient MECs dampened the impact of ErbB3 ablation, allowing lactation to proceed, albeit in a delayed fashion, through the expansion of $\mathrm{CK}^{+} / \mathrm{CK}^{+}$double-positive aMECs. These studies highlight the key roles played by ErbB3 and ErbB4 in establishing and maintaining milk production.

\section{Methods \\ Mice}

All animal husbandry and experiments were performed in accordance with protocols approved by the Vanderbilt University Institutional Animal Care Committee using humane procedures. ErbB3 ${ }^{F L}$ [48] and WAPi-Cre [49] mice have been described previously. All mice were inbred to, or generated on, the Friend Virus B-type (FVB) background. Mouse experiments were approved by the Vanderbilt Institutional Animal Care and Use Committee. Female virgin mice were bred at 10-12 weeks of age to WT FVB male mice. Mating pairs were separated upon identification of a semen plug, indicating 0.5 days post coitus (d.p.c.). Parturition indicated lactation day 0 (LO), and litters were normalized to eight pups per litter.

\section{Histological analysis}

Right \#4 inguinal mammary glands were formalin fixed and paraffin embedded, and sections $(5 \mu \mathrm{m})$ were stained with hematoxylin and eosin. In-situ terminal dUTP nick end-labeling (TUNEL) analysis was performed on paraffinembedded sections using the ApopTag kit (Millipore). Immunohistochemistry (IHC) on paraffin-embedded sections was performed using the following antibodies as described previously [50]: ErbB3 (C-17; Santa Cruz Biotechnology), Ki67 (Santa Cruz Biotechnology), P-Akt S473 (Cell Signaling Technologies), P-STAT5A/B (Neomarkers), and P-ErbB4 Tyr1056 (Cell Signaling Technologies). Immunodetection was performed using the Vectastain kit (Vector Laboratories) according to the manufacturer's instructions. Immunofluorescence staining was performed with primary and secondary antibodies diluted in 12\% Fraction-V BSA (Pierce) and slides were mounted in SlowFade mounting medium containing DAPI (Invitrogen). All fluorescent secondary antibodies were highly crossadsorbed, produced in goat, and used at a dilution of 1:200 for $20 \mathrm{~min}$ (Molecular Probes). Primary antibodies used were CK5 (10956, 1:500; Covance/Biolegend), CK8/ 18 (1:500; Fitzgerald Industries International), and ErbB3 (c-17, 1:200; Santa Cruz Biotechnology).

\section{Cell culture}

HC11 cells [51] were cultured in DMEM: F12 (1:1) medium supplemented with $10 \%$ fetal bovine serum (Life Science), insulin $(5 \mu \mathrm{g} / \mathrm{ml})$, dexamethasone $(10 \mu \mathrm{g} /$ $\mathrm{ml}$ ) (Sigma-Aldrich) and human EGF (5 ng/ml; R\&D Systems). To induce differentiation, cells were serum and EGF-starved for $24 \mathrm{~h}$, and then treated with $5 \mu \mathrm{g} / \mathrm{ml}$ mouse PRL (Preprotech). In some cases, cells were treated with Nrg1b (EGF-like domain) (R\&D Systems), neratinib, AZD6244, or BKM120 (all from SelleckChem). Where indicated, single-cell suspensions $\left(5 \times 10^{5}\right.$ cells $)$ were infected with $10^{6} \mathrm{pfu} / \mathrm{ml}$ of the adenoviral particles adenoviral myristoylated Akt1 (Ad.Akt ${ }^{\mathrm{myr}}$ ), adenoviral ErbB4 (Ad.ErbB4), and adenoviral green fluorescent protein (Ad.GFP), from Vector Biolabs. Knockdown of ErbB3 in HC11 cells using siRNA sequences was performed using $5 \mu \mathrm{M}$ siRNA against ErbB3 (SASI_Mm01_0031804, SASI_Mm01_0031805, and SASI_Mm01_0031806; SigmaAldrich) or a scrambled sequence (siScr) transfected with Lipofectamine 2000 (Invitrogen). Stable knockdown of ErbB3 was achieved by lentiviral transduction of LVP158 (Gentarget, Inc.). HC11 cells were transduced with lentiviral particles for $48 \mathrm{~h}$ prior to puromycin selection. Pooled clones of puromycin-resistant cells were expanded for analysis of ErbB3 knockdown prior to experimentation.

\section{Western blot analysis}

Mammary glands and cells were homogenized in icecold $50 \mathrm{mM}$ Tris (pH 7.4), $100 \mathrm{mM} \mathrm{NaF}, 120 \mathrm{mM} \mathrm{NaCl}$, $0.5 \%$ Nonidet P-40, $100 \mu \mathrm{M} \mathrm{Na} \mathrm{VO}_{4}$, and $1 \times$ protease inhibitor mixture (Roche), sonicated for $10 \mathrm{~s}$ on ice, and cleared by centrifugation at $4{ }^{\circ} \mathrm{C}, 13,000 \times g$ for $20 \mathrm{~min}$. Protein concentration was determined using the bicinchoninic acid assay (Pierce). Proteins were separated by SDS/PAGE and transferred to nitrocellulose membranes. Membranes were blocked in 3\% gelatin in TBS-T (Tris-buffered saline, $0.1 \%$ Tween-20) for $1 \mathrm{~h}$, incubated in primary antibody in $3 \%$ gelatin overnight at $4{ }^{\circ} \mathrm{C}$, washed with TBS-T, incubated in HRPconjugated anti-rabbit (sc-2375, 1:10,000; Santa Cruz Biotechnology) or anti-mouse IgG (ab97240, 1:5000; Abcam), washed with TBS-T, and then developed using ECL substrate (Pierce). The following primary antibodies were used: P-ErbB3 (sc-135654, 1:500; Santa Cruz Biotechnology), P-MAPK/Akt/S6/Rab11 cocktail (1:1000; Cell Signaling Technologies), total Akt (C67E7, 1:1000; Cell Signaling Technologies), actin (1:2000; Cell 
Signaling), STAT5A and P-STAT5A/B (93585 at 1:500 and C11C5 at 1:500, respectively; Cell Signaling Technologies), and cleaved caspase 3 (D175, 1:500; Cell Signaling Technologies).

\section{Gene expression analysis}

Total RNA was harvested from cells and mammary glands using RNeasy (Qiagen). RNA quality was assessed using the Agilent Analyzer. RNA $(1 \mu \mathrm{g})$ was reverse transcribed (RT2 First Strand Kit; Qiagen). Mouse primers for Stat5a, Erbb4, Erbb3, Csn2, and 36B4 were purchased from SABiosciences (Qiagen). Primer sequences are as follows: $\mathrm{mErbB3}$, forward $5^{\prime}$-CGAGAACTGCACCCAAGG and reverse 5'-TCTGCTTGGCCTAAACAGTCT; mStaa5A, forward 5'-CGCCAGATGCAAGTGTTGTAT and reverse 5 '-TCCTGGGGATTATCCAAGTCAAT; mCsn2, forward 5 '-GGCACAGGTTGTTCAGGCTT and reverse 5'-AAG GAAGGGTGCTACTTGCTG; and $\mathrm{mErbb4}$, forward 5'-CCATGGACCGGACCTGC and reverse 3'-GCTCC CTGTAGGCCATCTGG.

\section{Results \\ ErbB3 loss decreases expansion of the mammary epithelium during pregnancy}

We assessed Erbb3 mRNA levels in expression microarray datasets derived from mouse mammary glands harvested at distinct developmental time points of pregnancy and lactation [52] (Fig. 1a), revealing relatively low Erbb3 during early pregnancy (1-7 days post coitus (d.p.c.)) but approximately a 4-fold Erbb3 upregulation at mid-pregnancy (12 d.p.c.). High Erbb3 expression persisted through late pregnancy (18 d.p.c.) but decreased at parturition and lactation. We used immunohistochemistry (IHC) to identify the cell types of the mammary gland expressing ErbB3, confirming ErbB3 protein expression in developing alveoli (the milk-producing epithelial structures) (Fig. 1b). To investigate the impact of ErbB3 ablation from aMECs, we crossed mice harboring floxed $E r b b 3$ alleles $\left(E r b b 3^{F L / F L}\right)$ [48] with WAPi-Cre transgenic mice [49]. Compared to mammary glands from $\mathrm{ErbB}^{+/+} \mathrm{WAP}-\mathrm{Cre}$ mice (referred to here as $E r b B 3^{W T}$ ), which expressed ErbB3 abundantly in aMECs at 16.5 d.p.c. and at lactation day 1 (L1), mammary glands from $E r b B 3^{F L / F L} W A P$-Cre mice (referred to here as $E r b B 3^{K O}$ ) expressed potently reduced levels of ErbB3 (Fig. 1b; Additional file 1: Figure S1). Immunofluorescent staining of mammary glands harvested at 16.5 d.p.c. confirmed that ErbB3-positive MECs were also positive for cytokeratin 8 (K8) in ErbB3 ${ }^{W T}$ samples (Fig. 1c; Additional file 1 Figure S2). These findings are consistent with previous reports that ErbB3 is expressed primarily in luminal, but not basal, populations of the mammary epithelium [48].

Cre-mediated ErbB3 ablation decreased pregnancyinduced expansion of alveolar epithelial structures in mammary glands (Fig. 1d) by approximately 4-fold at 16.5 d.p.c. (Fig. 1e). Although epithelial area remained diminished in $E r b B 3^{K O}$ mammary glands through L10, the effect size between $E r b B 3^{K O}$ and $E r b B 3^{W T}$ diminished progressively. Consistent with the decreased epithelial density seen in $E r b B 3^{K O}$ mammary glands, pups nursed by $E r b B 3^{K O}$ dams weighed less than those nursed by $E r b B 3^{W T}$ dams at L3 and L10 (Fig. 1f). These data are in agreement with a previous report showing that ErbB3 signaling supports lactogenic expansion during pregnancy [47], and demonstrate that ErbB3 supports mammary gland development during pregnancy.

\section{ErbB3 loss decreases proliferation and cell survival of luminal, but not basal, MECs during pregnancy}

To understand ErbB3-regulated events that contribute to lactogenic mammary gland development, we used Ki67 IHC as a measure of cell proliferation. These studies revealed decreased Ki67 staining in $\operatorname{ErbB} 3^{K O}$ aMECs at 16.5 d.p.c., as compared to $\operatorname{ErbB} 3^{W T}$ (Fig. 2a; Additional file 1: Figure S3). By L5, however, the percentage of Ki67 aMECs was equal in $\operatorname{ErbB} 3^{K O}$ and $\operatorname{ErbB} 3^{W T}$ samples. Cell death of aMECs was measured in situ using terminal dUTP nick end-labeling (TUNEL) analysis, revealing markedly increased TUNEL ${ }^{+}$cells in $E r b B 3^{K O}$ mammary glands at 16.5 d.p.c. and L1, although no differences in the percentage of TUNEL ${ }^{+}$MECs were seen by L5 (Fig. 2b; Additional file 1: Figure S4).

Immunofluorescent staining for $\mathrm{K} 8$ and cytokeratin 5 (K5) was used to discriminate between the $\mathrm{K}^{+}$populations of luminal MECs, the $\mathrm{K}^{+}$population of myoepithelial MECs and mammary stem cells, and K8 ${ }^{+} \mathrm{K}^{+}$double-positive cells, which are thought to represent a bipotential MEC progenitor population and may contribute to the plasticity that exists between the distinct MEC lineages. Consistent with the reported histological architecture of the mouse mammary gland, ErbB3 ${ }^{W T}$ mammary glands harvested at $\mathrm{L} 1$ displayed basal localization of $\mathrm{K}^{+}$MECs and $\mathrm{K} 8$ ${ }^{+} \mathrm{K}^{+}$double-positive MECs (yellow arrows, Fig. 2c) and apical localization of $\mathrm{K}^{+}$MECs. In contrast, $E r b B 3^{K O}$ samples harvested at L1 harbored increased double-positive $\left(\mathrm{K}^{+}{ }^{+} \mathrm{K}^{+}\right)$MECs, which were often localized to apical positions (white arrows, Fig. 2c). The increased numbers of $\mathrm{K}^{+} \mathrm{K}^{+}$double-positive MECs appeared to occur at the expense of luminal $\left(\mathrm{K}^{+}\right)$ MECs, since $\mathrm{K}^{+}$MECs were decreased in $\operatorname{ErbB} 3^{K O}$ samples as compared to controls (Fig. 2d). This finding that ErbB3 depletion decreases the population of $\mathrm{K}^{+}$MECs is consistent with previous observations that ErbB3 loss from the mammary ductal epithelium caused a loss of $\mathrm{K}^{+}$luminal MECs, with a compensatory expansion of the $\mathrm{K}^{+}$population [48]. 


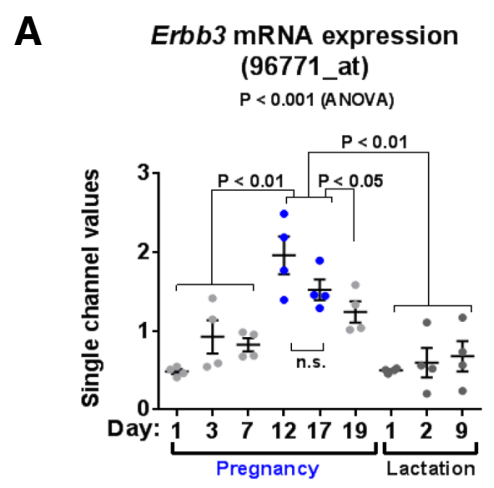

B
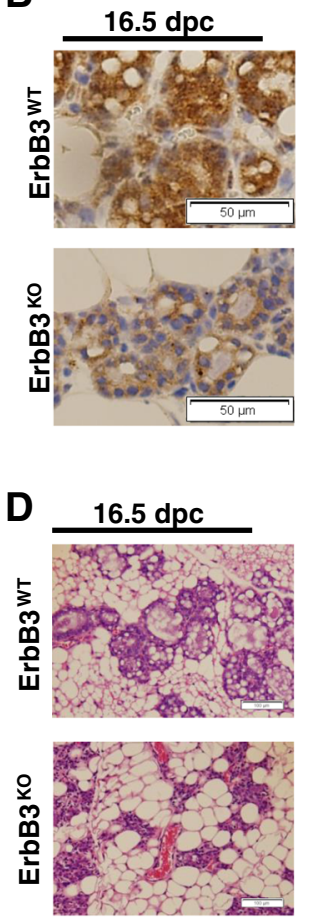
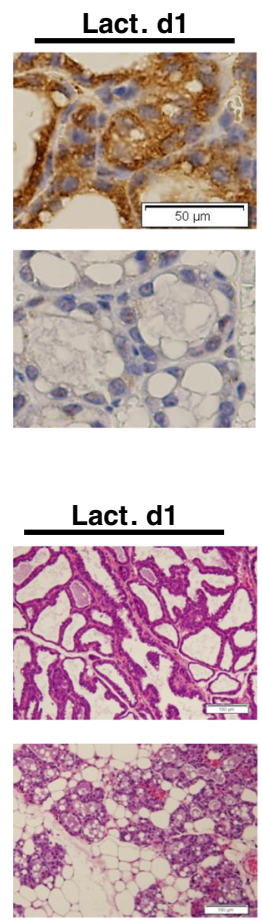
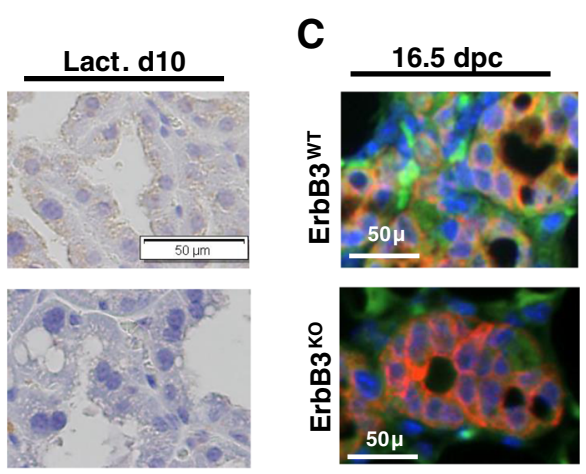

K8 (red) I

ErbB3 (green)

E

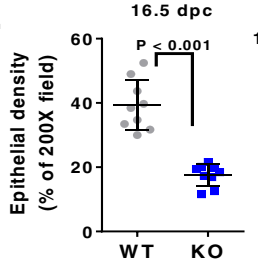

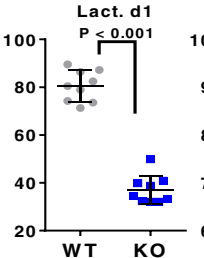

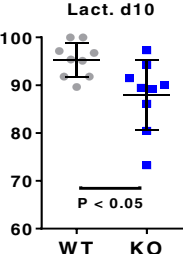

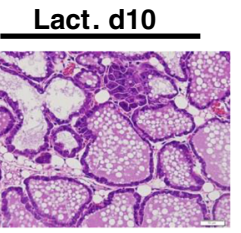

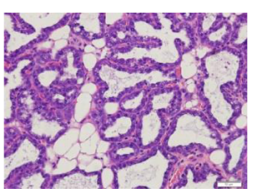

Fig. 1 ErbB3 loss decreases expansion of the mammary epithelium during pregnancy. a Erbb3 mRNA expression is maximal during late puberty in mice. Data and plot extracted and generated from the National Center for Biotechnology Information Gene Expression Omnibus dataset GDS2843 using the probe set 96771_at. Details of the study published in [60]. Data represents indicated single channel transformed counts, with blue data signifying elevated levels of Erbb3. b-e Mammary glands harvested from 12-15-week-old mice at 16 d.p.c. and L1. N = 9 per time point. Representative images are shown, original magnification is $400 \times$. b $\mathrm{HHC}$ detection of ErbB3. c IF staining of K8 (red) and ErbB3 (green). Sections were counterstained with DAPI. d Histological sections stained with hematoxylin and eosin. e Quantitation of epithelial density in randomly selected $200 \times$ fields. Using digital images, epithelial areas were circumscribed to generate a closed polygon to generate an automated calculation of the polygon area. Each data point represents the average of three randomly chosen fields per sample; midlines are the average of all biological replicates \pm SD. $P$ values calculated using Student's unpaired two-way $t$ test. $\mathbf{f}$ Litters were normalized to eight pups each, then pups were weighed postnatally at days 3 and 10. Each data point represents the average pup weight of a single litter; midlines are the average of all litters within the group. $N=12$ litters. Student's unpaired, two-way $t$ test. $d p c$ days post coitus, Lact $d$ lactation day (Color figure online) 
A

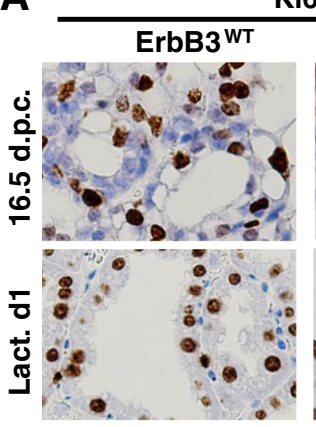

Ki67
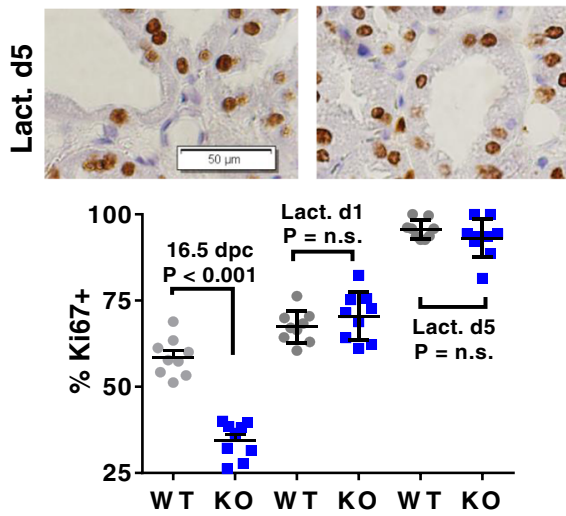

C

K5 (red) / K8 (green)

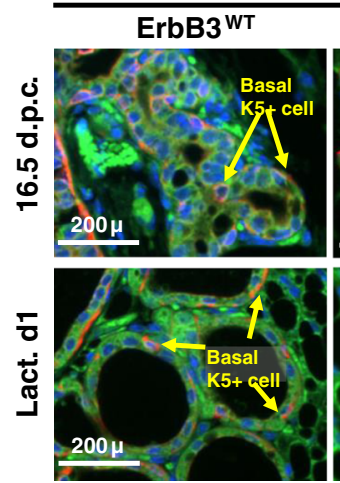

B
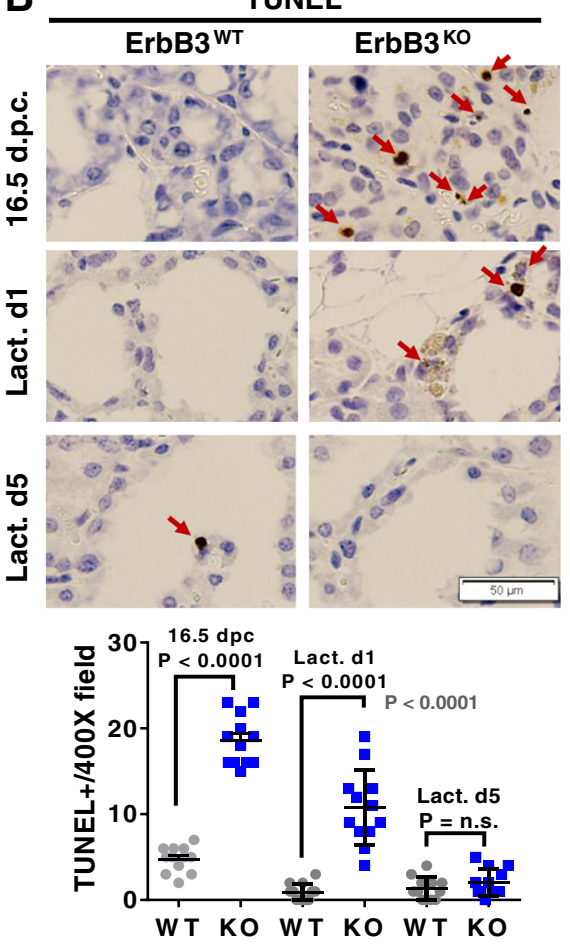

D

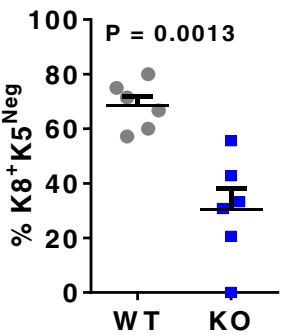

Fig. 2 ErbB3 loss decreases proliferation and cell survival of luminal, but not basal, MECs during pregnancy. Mammary glands harvested from 12-15-week-old mice at 16.5 d.p.c., L1, and L5. Representative images are shown. Original magnification is 400x. P values calculated using Student's unpaired two-way $t$ test. a $1 \mathrm{HC}$ detection of Ki67. $N=9$. Lower panel: percentage of MECs that were Ki67 ${ }^{+}$. Each data point represents the average of two random 400x fields from a single tumor; midlines are average of samples within the group \pm SD. $\mathbf{b}$ TUNEL analysis, $N=12$. Each data point represents the average of two random 400x field from a single Mammary Gland!; midlines are the average of samples within the group \pm SD. c. IF staining of K5 (red) and K8 (green). Sections were counterstained with DAPI. Yellow arrows indicate basal location of K5 ${ }^{+}$ cells; white arrows indicate apically localized $\mathrm{K}^{+}$cells. $\mathbf{d}$ Quantitation of the percentage of MECs that were K8-positive/K5-negative. $N=5$. Each data point represents the average value of three random $400 \times$ fields per sample; midlines are the average of all biological replicates \pm SD. $d p c$ days post coitus, Lact $d$ lactation day, TUNEL terminal dUTP nick end-labeling (Color figure online)

ErbB3 drives MEC survival through the PI3K-to-Akt signaling pathway during pregnancy

Given that ErbB3 is a potent driver of PI3K/Akt signaling in ductal luminal MECs [48] and in luminal breast cancers [53], we examined P-Akt in mammary glands harvested at 16.5 d.p.c., L1, and L5. Consistent with previous reports of Akt signaling during lactogenic differentiation, we found abundant Akt phosphorylation in alveolar structures of the mammary glands harvested from $\operatorname{ErbB} 3^{W T}$ mice at each time point (Fig. 3a; Additional file 1: Figure S5). In contrast, Akt phosphorylation was significantly diminished at 16.5 d.p.c. in $E r b B 3^{K O}$ samples, but began to recover by $\mathrm{L} 1$ and we observed full restoration of P-Akt by L5.

To determine the role of Akt signaling as an ErbB3 effector driving MEC survival during lactogenesis, we 

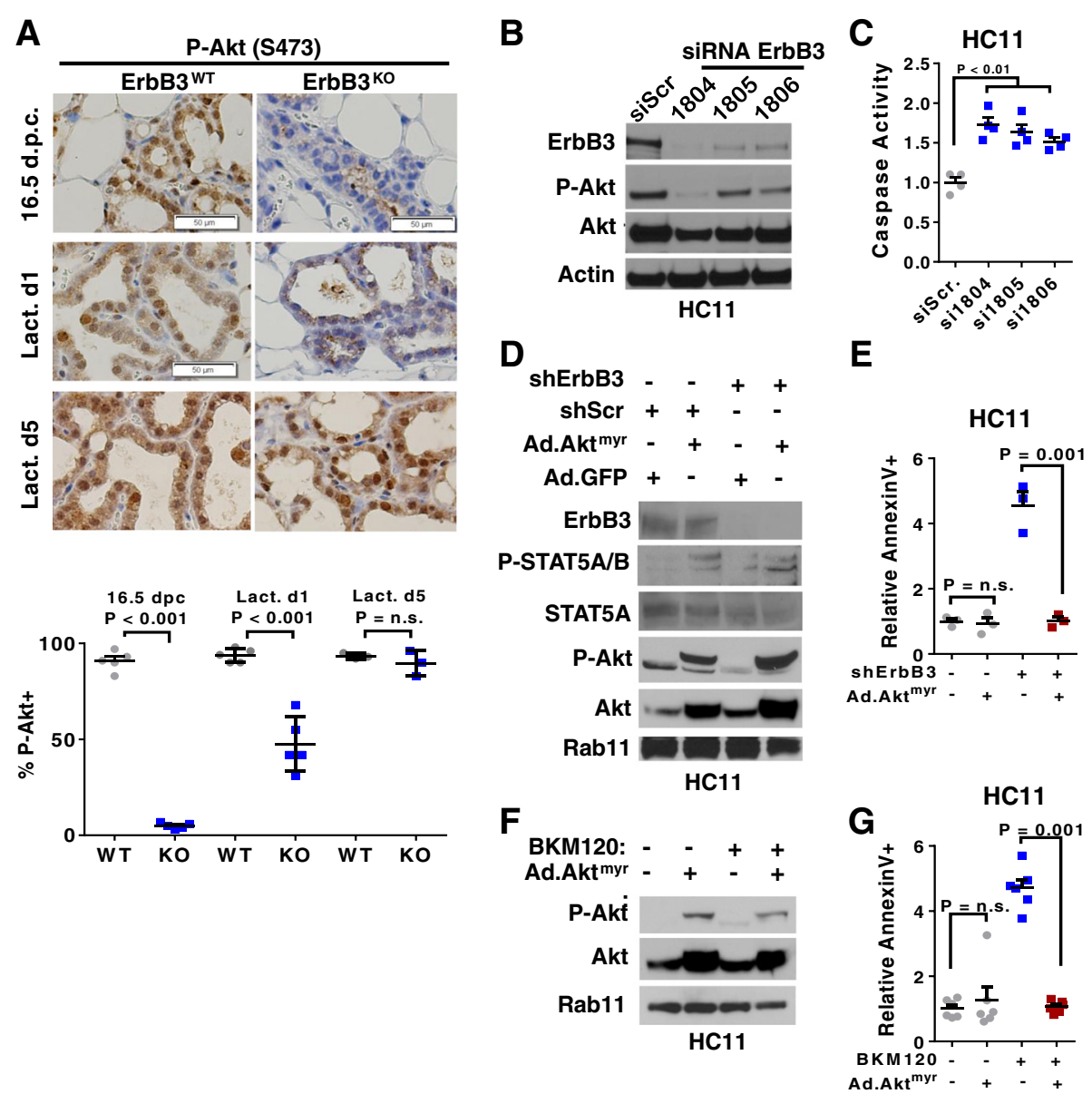

Fig. 3 ErbB3 drives MEC survival through the PI3K-to-Akt signaling pathway during pregnancy. a Mammary glands harvested from 12-15-week-old mice at 16.5 d.p.c., L1, and L5, and stained using IHC for P-Akt Serine 473. Representative images are shown. Original magnification is 400x. Lower panel: percentage of MECs that were $\mathrm{P}^{+}$. Each data point represents the average of two random $400 \times$ fields from a single tumor; midlines are the average of samples within the group \pm SD. $P$ values calculated using Student's unpaired two-way $t$ test. $N=5$. b, c HC11 cells harvested for analysis $72 \mathrm{~h}$ after transfection with three distinct siRNA sequences targeting ErbB3, or a scrambled siRNA sequence (siScr). $\mathbf{b}$ Western blot analysis using antibodies listed at the left. Representative images are shown, repeated three times. c Caspase 3/7 activity measured using Caspase-Glo, corrected for total protein content, and shown relative to the caspase 3/7 activity measured in cells transfected with siscr sequences. Experiments were assessed in triplicate and repeated four times. Data points are the average of the experimental triplicates; midlines are the average $( \pm$ SD) of the biological replicates. Student's unpaired $t$ test. d, e HC11 cells stably transduced with lentivirus encoding ErbB3 shRNA (shErbB3) or shScr, then transduced with Ad.Akt ${ }^{\mathrm{Myr}}$ or Ad.GFP, and harvested for analysis $48 \mathrm{~h}$ later. $\mathbf{d}$ Western blot analysis using antibodies listed at the left. Representative images are shown, repeated three times. e Cell cultures stained with Annexin V-FITC to detect apoptotic cells. Experiments were assessed in triplicate and repeated four times. Data points are the average of the experimental triplicates across experiments; midlines are the average ( \pm SD) of the biological replicates. Student's unpaired $t$ test. $\mathbf{f}, \mathbf{g ~ H C 1 1}$ cells transduced with Ad.Akt ${ }^{\mathrm{Myr}}$ or Ad.GFP. At $48 \mathrm{~h}$ post transduction, cells were treated with BKM120 (1 $\mu \mathrm{M})$ for $6 \mathrm{~h}(\mathbf{f})$ or $16 \mathrm{~h}(\mathbf{g})$. f Western blot analysis using antibodies listed at the left. Representative images are shown, repeated three times. $\mathbf{g}$ Cell cultures stained with Annexin V-FITC to detect apoptotic cells as described in (e). $d$ lactation day

utilized HC11 cells, an immortalized aMEC cell line harvested during pregnancy from a Balb/C mouse. Although immortalized, these cells retain their ability to undergo lactogenic differentiation in culture [51], including PRL-inducible expression of milk proteins and formation of fluid-filled acini. We knocked down ErbB3 in HC11 cells using three distinct siRNA sequences, each of which potently reduced ErbB3 protein levels (Fig. 3b). Similar to what was seen in mouse mammary glands in vivo, loss of ErbB3 in HC11 cells decreased
Akt phosphorylation, and increased activation of caspases 3 and 7 (Fig. 3c), irreversible molecular switches that activate programmed cell death. Next, we generated lentiviral vectors for shRNA-mediated stable knockdown of ErbB3 in HC11 cells, which decreased ErbB3 protein expression in pooled selection-resistant clones as compared to $\mathrm{HC} 11$ cells expressing a scrambled nontargeting shRNA (shScr; Fig. 3d). ErbB3 knockdown efficiently reduced phosphorylation of Akt. We restored Akt activity in HC11-shErbB3 using adenoviral expression 
of $\mathrm{Akt}^{\mathrm{myr}}$ (Ad. Akt ${ }^{\mathrm{myr}}$ ), which rescued Akt phosphorylation in HC11-shErbB3 cells. ErbB3 knockdown by shRNA increased HC11 apoptosis over what was seen in shScr-expressing cells, as measured by Annexin V staining (Fig. 3e). However, Ad.Akt ${ }^{\text {myr }}$ restored survival of HC11shErbB3 cells, suggesting that ErbB3 utilizes Akt signaling to drive aMEC survival.

PI3K signaling activates Akt in numerous cell types, including ductal luminal MECs [47, 48]. To determine whether PI3K is required to activate Akt in aMECs, we used the pan-PI3K p110 subunit kinase inhibitor BKM120 to block PI3K signaling in $\mathrm{HC} 11$ cells, which impaired Akt phosphorylation (Fig. 3f). Ad.Akt ${ }^{\mathrm{myr}}$ restored Akt phosphorylation in BKM120-treated cells. Similar to what was seen upon ErbB3 depletion, PI3K inhibition using BKM120 potently increased HC11 apoptosis (Fig. 3g). Ad.Akt ${ }^{\text {myr }}$ decreased $\mathrm{HC} 11$ cell apoptosis following treatment with BKM120. Since ErbB3 signaling also activates the mitogen activated protein kinase (MAPK) pathway in ductal luminal MECs during puberty [48], we assessed the impact of MAPK inhibition on HC11 cell survival by treating cells with the MEK inhibitor AZD6244. MEK inhibition blocked Erk phosphorylation, as expected (Additional file 1: Figure S6A). In contrast to what was seen with PI3K inhibition, MEK inhibition did not induce apoptosis in HC11 cells (Additional file 1: Figure S6B), suggesting that aMECs rely on ErbB3 signaling to drive PI3K/Akt-mediated cell survival during lactogenic expansion.

\section{Decreased STAT5-dependent differentiation of ErbB3- deficient aMECs}

Several reports describe the reciprocal relationship between Akt activation and STAT5A activation in the mammary gland $[41,42]$. Importantly, STAT5A is a transcription factor that drives aMEC expansion and lactogenic differentiation during pregnancy $[18,19,54]$. Because Akt activity was profoundly attenuated in $E r b B 3^{K O}$ aMECs during pregnancy, we assessed STAT5 activity in $E r b B 3^{K O}$ mammary glands by examining STAT5 phosphorylation. We found an abundance of cells expressing P-STAT5A/B in mammary glands harvested from $E r b B 3^{W T}$ mice at 16.5 d.p.c., L1, and L5 (Fig. 4a; Additional file 1: Figure S7). In contrast, few aMECs expressed P-STAT5A/B in ErbB $3^{K O}$ mammary glands at 16.5 d.p.c. Although the percentage of aMECs expressing P-STAT5A/B remained significantly reduced in $E r b B 3^{K O}$ mammary glands at L1, the percentage of cells expressing P-STAT5A/B in $E r b B 3^{K O}$ mammary glands at L5 was similar to what was seen in stage-matched $\operatorname{ErbB} 3^{W T}$ samples, analogous to the temporal recovery of P-Akt in $E r b B 3^{K O}$ samples. We measured Stat5a gene expression in whole mammary glands. To account for reduced input of luminal MECs in $E r b B 3^{K O}$ samples, all values were corrected for expression of $C k 8$, the gene encoding $\mathrm{K} 8$. These results revealed reduced Stat5a mRNA expression in $E r b B 3^{K O}$ samples at 16.5 d.p.c. and L1 (Fig. 4b), although Stat5a expression was similar in $E r b B 3^{K O}$ and $E r b B 3^{W T}$ samples at L10. Because STAT5A binds to the promoters of several prominent milk protein encoding genes, including $\operatorname{Csn} 2$ (which encodes $\beta$-casein), to drive their expression during lactogenesis and lactation, we examined gene expression of Csn2. Similar to what was seen with Stat5a expression, $C s n 2$ was decreased in $E r b B 3^{K O}$ samples at 16.5 d.p.c., L1, and L10, although Csn2 levels progressively increased throughout lactation.

We used HC11-shErbB3 and HC11-shScr cells to investigate ErbB3-inducible signaling pathways that regulate lactogenic differentiation. Serum and EGF-starved HC11-shScr cells were treated with PRL for $24 \mathrm{~h}$ to initiate lactogenic differentiation, as described previously [51], which upregulated Erbb3, Stat5a, and Csn2 transcripts (Fig. 4c), similar to the Erbb3 induction in mammary glands seen during mid-pregnancy (Fig. 1a) when systemic hormones induce lactogenic expansion of the mammary gland. In contrast, HC11-shErbB3 cells cultured under these same conditions failed to induce Erbb3, Stat5a, and Csn2 (Fig. 4c).

We next tested the role of PI3K signaling in lactogenic HC11 differentiation, using the PI3K inhibitor BKM120. Serum and EGF-starved HC11 cells cultured for $24 \mathrm{~h}$ with BKM120 revealed upregulation of Erbb3 mRNA (Fig. 4d), consistent with previous observations that PI3K inhibition causes increased Erbb3 gene expression in breast, lung, and intestinal tumor cells $[56,57]$. In fact, BKM120 enhanced PRL-mediated induction of Erbb3 in $\mathrm{HC} 11$ cells. Further, PI3K inhibition using BKM120 did not interfere with PRL-mediated induction of Stat $5 a$ or Csn 2 transcripts. While PRL-treated HC11shScr cells generated fluid-filled acini, a morphological feature consistent with $\mathrm{HC} 11$ cell differentiation [12, 21, 28], HC11-shErbB3 cells were unable to generate these fluid-filled acini (Fig. 4e). However, PI3K inhibition in HC11-shScr cells using BKM120 did not impair formation of fluid-filled acini, although these acini were smaller than what was seen in control samples, consistent with the qualitatively smaller size of the BKM120 cells adjacent to the acini. Further, Akt ${ }^{\text {myr }}$ expression in HC11-shErbB3 cells only modestly rescued STAT5A protein expression under basal conditions (Fig. 4f). These results suggest that, while ErbB3 signaling is required for induction of Stat 5 a and Csn2, PI3K/Akt signaling is not.

\section{ErbB4 loss compensates for ErbB3 loss in aMECs during pregnancy and lactation}

ErbB3 heterodimerization is induced by the NRG ligands. We grew HC11 cells to confluence, then serum and EGFstarved the cells for $24 \mathrm{~h}$ and treated cells with PRL in the presence or absence of NRG1 (2 ng/ml), revealing 


\section{A}
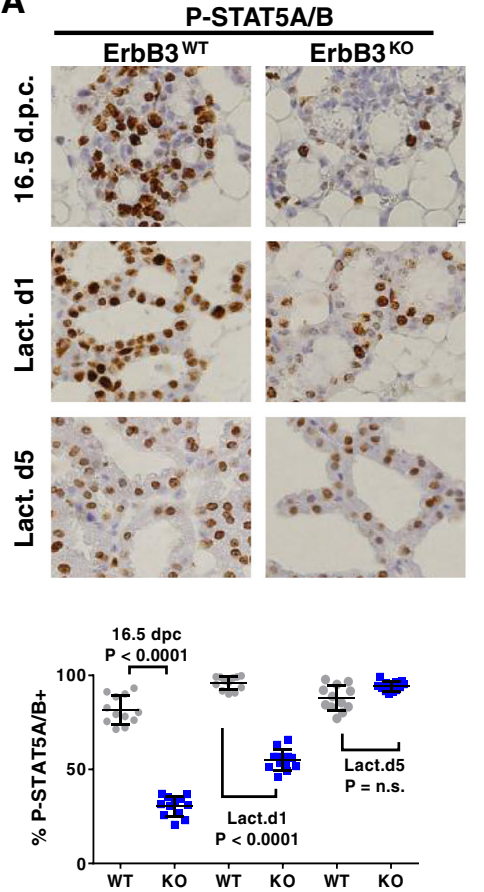

E
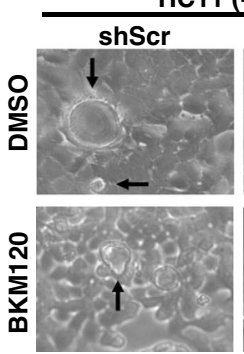

B
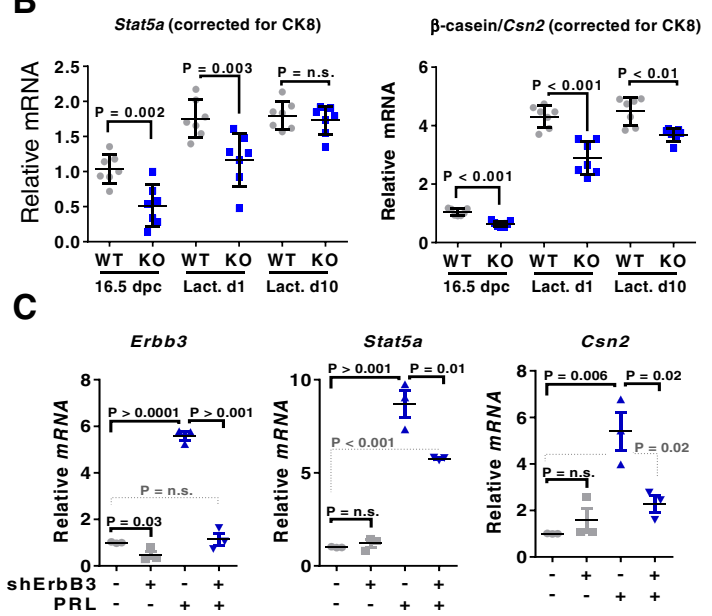

Csn2

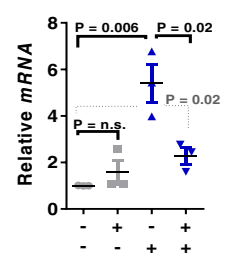

D

Erbb3
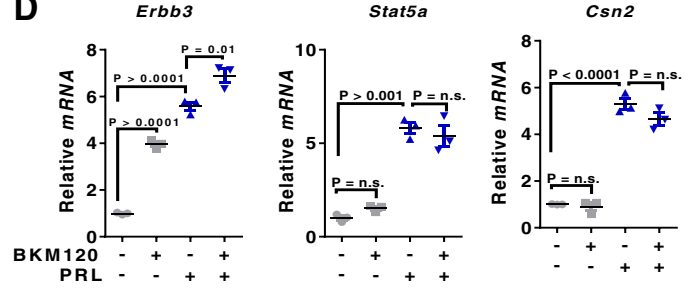

$\mathbf{F}$

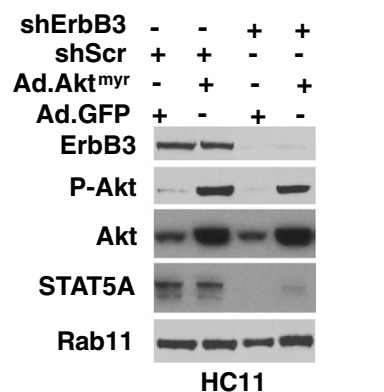

Fig. 4 Decreased STAT5-dependent differentiation of ErbB3-deficient aMECs. a, b Mammary glands harvested from 12-15-week-old mice at 16.5 d.p.C., L1, and L5. a Samples stained using IHC for P-STAT5A/B. Representative images are shown, and original magnification is 400X. Lower panel: percentage of MECs that were P-STAT5A/B ${ }^{+}$. Each data point represents the average of two random 400x fields from a single tumor; midlines are the average of samples within the group \pm SD. $P$ values calculated using Student's unpaired two-way $t$ test. $N=12$. $\mathbf{b}$ Whole tissue RNA assessed by RT-qPCR for Stat5a, Csn2, and Ck8. Relative transcript levels calculated using the $\Delta \Delta C \mathrm{Ct}$ method, internally correcting for $36 B 4$ gene expression. Values are shown relative to the average value obtained for ErbB3WT samples harvested at 16.5 d.p.c. Each sample was assessed in triplicate, with the average triplicate value shown by a single data point. $N=7$ per time point. c-e HC11-shErbB3 and HC11-shScr cells (c, e) and parental HC11 cells (d) were serum and EGF-starved for $24 \mathrm{~h}$, followed by treatment with PRL, with or without BKM120 (1 $\mu \mathrm{M})$ for $24 \mathrm{~h}$. c, d Whole cell RNA assessed by RT-qPCR for expression of Stat5a and Csn2 and quantitated as described for (b). e Representative image of serum/EGF-starved cells treated for $24 \mathrm{~h}$ with PRL, revealing fluid-filled acini (black arrows) in ShScr cells, but not in shErbB3 cells. $\mathbf{f} \mathrm{HC11}$-shErbB3 and HC11-shScr cells transduced with Ad.Akt ${ }^{\mathrm{Myr}}$ or Ad.GFP. At $48 \mathrm{~h}$ after transduction, cells were serum and EGF-starved, then treated with PRL for $24 \mathrm{~h}$, and assessed by western blot analysis using antibodies shown at the left. dpc days post coitus, Lact $d$ lactation day, PRL prolactin (Color figure online)

increased P-ErbB3, total STAT5A, and P-STAT5A/B at 24 h (Fig. 5a). Treatment with the pan-ErbB family inhibitor neratinib $(0.25 \mu \mathrm{M})$ blocked NRG1-induced phosphorylation of ErbB3 and STAT5A/B, and largely reduced NRG1-mediated total STAT5A induction. Neratinib treatment also blocked basal and NRG1-induced Akt phosphorylation, while increasing caspase 3 cleavage. Similarly, BKM120 treatment blocked basal and NRG1induced Akt phosphorylation, and increased caspase 3 cleavage. However, levels of STAT5A and P-STAT5A/B remained elevated in BKM120-treated HC11 cells. Further, NRG1 treatment of HC11-shErbB3 cells for $24 \mathrm{~h}$ partially rescued the induction of cell death caused by ErbB3 ablation (Additional file 1: Figure S8). These data suggest that NRG-induced ErbB3 signaling potently induces both PI3K/Akt and STAT5A signaling pathways, but that the PI3K/Akt signaling may not be necessary for the induction of STAT5A during early aMEC expansion. 

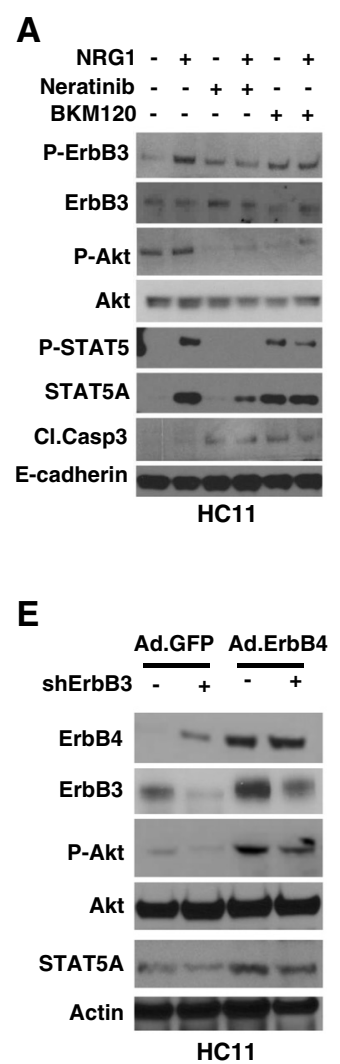

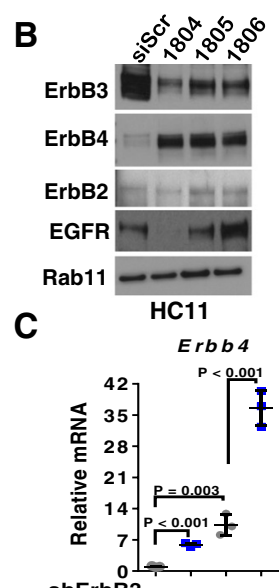

$\mathbf{F}$

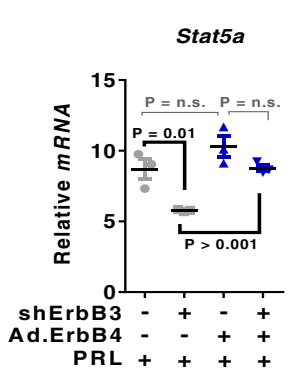

D

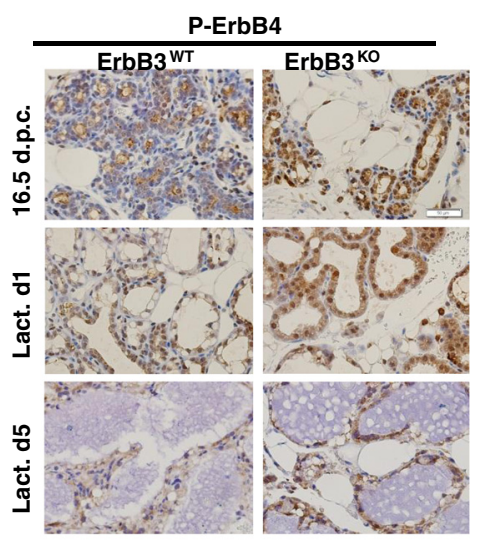

G

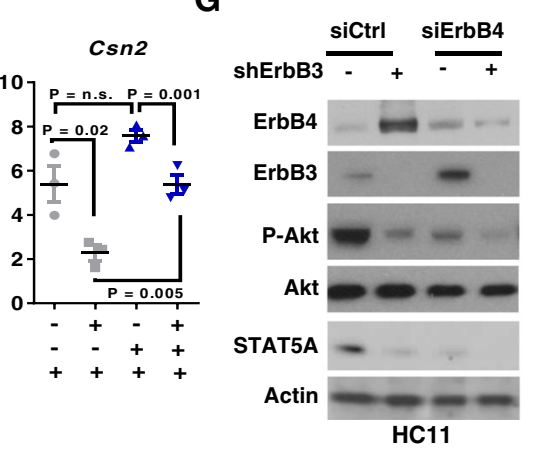

Fig. 5 ErbB4 loss compensates for ErbB3 loss in aMECs during pregnancy and lactation. a HC11 cells serum and EGF-starved for $24 \mathrm{~h}$ were treated with PRL for $24 \mathrm{~h}$, in the presence of NRG1 (2 ng/ml), neratinib $(250 \mathrm{nM})$, and/or BKM120 (500 nM) as indicated. Whole cell lysates assessed by western blot analysis for proteins indicated at the left. $\mathbf{b} \mathrm{HC} 11$ cells harvested for analysis $72 \mathrm{~h}$ after transfection with three distinct siRNA sequences targeting ErbB3, or a scrambled siRNA sequence (siScr). Western blot analysis using antibodies listed at the left. Representative images are shown, repeated three times. c HC11-shErbB3 and HC11-shScr cells serum and EGF-starved for $24 \mathrm{~h}$, followed by treatment \pm PRL for $24 \mathrm{~h}$. Whole cell RNA assessed by RT-qPCR for expression of Erbb4 and quantitated as described for Fig. 4b. d Samples stained using IHC for P-ErbB4 Tyr1056. Representative images are shown, and original magnification is 400X. N = 12. e, f HC11-shErbB3 and HC11-shScr cells transduced with Ad.ErbB4 or Ad.GFP. At $48 \mathrm{~h}$ after transduction, cells were serum and EGF-starved, and then treated with PRL for $24 \mathrm{~h}$. e Cells assessed by western blot analysis using antibodies shown at the left. $\mathbf{f}$ Whole cell RNA assessed for expression of Stat5a and Csn2 and quantitated as described in Fig. 4b. g HC11-shErbB3 and HC11-shScr cells were transfected with control siRNA sequences (siCtrl) or siRNA sequences targeting ErbB4 (siErbB4). At $72 \mathrm{~h}$ after transfection, cells were serum and EGF-starved, then treated with PRL for $24 \mathrm{~h}$. Cells assessed by western blot analysis using antibodies shown at the left. dpc days post coitus, Lact $d$ lactation day, PRL prolactin

Because NRG ligands also bind to and activate ErbB4, a heterodimeric partner of ErbB3 that promotes lactogenic differentiation, we measured ErbB4 expression levels in $\mathrm{HC} 11$ cells expressing siRNA sequences against ErbB3 at $72 \mathrm{~h}$ post transfection, revealing increased expression of ErbB4 upon depletion of ErbB3 (Fig. 5b). These results were confirmed in serum and EGF-starved HC11-shErbB3 cells, revealing increased Erbb4 gene expression levels over what was seen in HC11-shScr cells (Fig. 5c). PRL increased Erbb4 expression in HC11-shScr cells, and to an even further extent in HC11-shErbB3 cells. These results support the idea that NRG-mediated signaling through ErbB4 may compensate for ErbB3 ablation, resulting in increased signaling though PI3K/Akt, and inducing expression and activity of STAT5A.
We tested this hypothesis first by assessing expression and activity of the Cyt-1 isoform of ErbB4. ErbB4 harbors two splice variations in its intracellular domain. The Cyt- 1 isoform harbors a PI3K-binding site at Tyr 1056, which requires phosphorylation in order to support an interaction with PI3K. Importantly, the Cyt-1 isoform is a potent driver of lactogenic differentiation. In contrast, the Cyt-2 isoform lacks the PI3K binding motif, and is a less potent activator of lactogenic differentiation. IHC-mediated detection of P-ErbB4 (Tyr 1056) was used to detect the presence of activated ErbB4-Cyt1 in mammary gland sections, revealing increased P-ErbB4 in $E r b B 3^{K O}$ mammary glands as compared to $E r b B 3^{W T}$ mammary glands at late pregnancy and L1 (Fig. 5d). 
Next, we overexpressed full-length ErbB4 (Cyt-1) in HC11-shErbB3 cells to determine whether ErbB4 upregulation might compensate for ErbB3 loss. Although stable knockdown of ErbB3 in HC11-shErbB3 cells resulted in ErbB4 upregulation, ErbB4 levels were increased much further upon transduction with adenoviral ErbB4 (Ad.ErbB4, Fig. 5e). ErbB4 overexpression in HC11-shErbB3 increased STAT5A and P-Akt expression, consistent with the idea that ErbB4 signaling supports PI3K signaling to Akt, and enhances lactogenic induction of STAT5A. Additionally, Csn2 expression was reduced in HC11-shErbB3 cells transduced with Ad.GFP, but Ad.ErbB4 rescued Csn2 levels in HC11-shErbB3 cells (Fig. 5f). Conversely, siRNA-mediated knockdown of ErbB4 caused ErbB3 upregulation in HC11-shControl cells (Fig. 5g). Despite robust ErbB3 expression in cells depleted of ErbB4, both P-Akt and STAT5A levels remained low, suggesting that ErbB3 and ErbB4 may operate as a functional heterodimeric unit to promote signaling that drives lactogenic differentiation. Further, elimination of NRG signaling through the combined knockdown of both ErbB3 and ErbB4 produced an even greater inhibitory effect on P-Akt and STAT5A. These findings suggest that the NRG receptors, ErbB3 and ErbB4, cooperatively enhance STAT5A and P-Akt signaling during lactogenic expansion and differentiation of the mouse mammary epithelium, and that loss of ErbB3 can be compensated for, at least partially, by increased signaling through ErbB4.

\section{Discussion}

We demonstrate here, using aMEC-specific ErbB3 ablation, that ErbB3 engages two key molecular signaling pathways at mid-pregnancy in the mammary gland, STAT5A and PI3K/Akt, which regulate two nonoverlapping aspects of lactogenic development during midpregnancy. We show that STAT5 signaling is a critical driver of lactogenic differentiation downstream of ErbB3, while PI3K/Akt signaling downstream of ErbB3 is needed for survival of the rapidly expanding aMEC population during pregnancy. These findings are consistent with a study in which ErbB3-to-PI3K signaling was eliminated through knock-in of an ErbB3 mutant lacking all PI3K binding motifs [47]. Interestingly, previous studies confirm that ErbB3 is required in luminal progenitor populations [48], which may give rise to early alveolar progenitor MECs. Because the previous study used a systemic ErbB3 mutant knock-in, then it is possible that impaired ErbB3-PI3K signaling would have altered the luminal progenitor population of MECs prior to commitment to the alveolar lineage, indirectly decreasing the aMEC population, interfering with lactogenesis, and potentially confounding the results. The studies performed herein addressed this possibility, using a Cre-expressing model confined to the committed alveolar lineage [49], and thus sparing ErbB3 expression in any luminal progenitor populations that might not yet be committed to the alveolar lineage. However, the results shown here largely recapitulate what was seen with the systemic ErbB3 mutant knockin model, supporting the notion that ErbB3 drives survival of luminal aMECs even after lineage specification.

We further distinguish our findings from those using the ErbB3 mutant knock-in model, as well as the ErbB3null mammary bud transplantation model, by our observations that complete ErbB3 disruption leads to decreased expression and phosphorylation of STAT5A in aMECs. This phenotype may have been missed in the previous models, perhaps because the knock-in ErbB3 mutant remains capable of ligand-induced heterodimerization with other ErbB family members, which would be capable of NRG-mediated ErbB3-ErbB4 signaling, which was potentially sufficient to induce STAT5A upregulation. This hypothesis is supported by our observations here that ErbB4 can partially, but not fully, compensate for ErbB3 loss.

The PI3K/Akt pathway is a key signaling node for lactogenic expansion and differentiation of the luminal mammary epithelium. Numerous signaling pathways that regulate lactogenic development converge on PI3K/Akt, including the insulin-like growth factor 1 receptor (IGF1R), RANKL and RANK, integrins, and PRLR-to-JAK2-toSTAT5A pathways $[8,11,14,33,44]$. In fact, transgenic mice overexpressing Akt or expressing constitutively active $\mathrm{Akt}^{\mathrm{myr}}$ in the mammary epithelium displayed increased aMEC survival, delaying the onset of MEC apoptosis at weaning [40, 41, 43, 45]. Although cell survival was not affected during pregnancy or lactation per se, increased activity of Akt aberrantly increased glucose uptake, glycolysis, and lipid production by aMECs, causing milk stasis and insufficient lactation [43], suggesting that Akt supports functions beyond cell survival in aMECs.

We show here that ErbB3 is expressed in mammary glands at mid-pregnancy, a time point when NRG ligands [23, 29, 31], ErbB4 [20, 26, 27], and STAT5 [15, 18, 19, 54] are induced. These findings suggest that ErbB3 may participate, perhaps as a heterodimeric partner of ErbB4, in the signaling cascade that activates STAT5A expression and phosphorylation, while also potently activating Akt phosphorylation at mid-pregnancy. This was confirmed in experiments in which ErbB4 upregulation rescued Akt and STAT5A dysregulation in response to ErbB3 ablation, whereas ErbB4 knock-down exacerbated the defects in Akt and STAT5A signaling caused by ErbB3 depletion (Fig. 5). This does not rule out the possibility that other EGFR family RTKs or ligand-activated PRLR might interact with ErbB3 and/or ErbB4 during lactogenesis, either as heterodimers or as multimeric signaling units. Because transgenic mice expressing a mammary-specific 
dominant-negative ErbB2 mutant have defective aMEC expansion and milk production [58], while mice lacking the EGFR ligands amphiregulin or EGF display reduced aMEC growth during pregnancy [59], it is possible that EGFR and/or ErbB2 might play a supporting role in aMEC expansion during pregnancy. This is an attractive hypothesis, given that ErbB4 upregulation occurred rapidly in $E r b B 3^{K O}$ mammary glands, as early as 16.5 d.p.c., but restoration of STAT5A and P-Akt was not evident until lactation day 1 . However, we did not find compensatory upregulation of ErbB2 expression in HC11 cells expressing shErbB3 (Additional file 1: Figure S9A) or in $\mathrm{ErbB}^{\mathrm{KO}}$ mammary glands (Additional file 1: Figure S9B).

Because previous reports suggest that ErbB4 can exist within a physical complex with PRLR, leading to NRGinduced PRLR activation, and conversely PRL-dependent ErbB4 phosphorylation [12], it is possible that ligandactivated PRLR could trans-activate ErbB4, resulting in low levels of ErbB4 activity that may partially compensate for ErbB3 loss. Consistent with this idea, treatment of HC11 cells with PRL induced low levels of ErbB4, ErbB3, and STAT5A/B phosphorylation (Additional file 1: Figure S10A, B), suggesting some level of cross-talk between PRL and ErbB RTKs. However, PRL treatment did not induce Akt phosphorylation. Further, ErbB3 knockdown interfered with PRL-mediated STAT5A/B phosphorylation, suggesting an important role for ErbB3 in PRL-mediated STAT5A/B phosphorylation, at least in the setting of a 30-min PRL treatment.

The observation that ErbB4 upregulation partially alleviated the impact of ErbB3 loss upon Akt phosphorylation and cell survival is consistent with previous studies demonstrating that full-length ErbB4 (the Cyt-1 isoform) harbors a PI3K binding motif capable of PI3K activation when phosphorylated at Tyr-1056. Notably, we identified potent upregulation of P-ErbB4 Tyr-1056 in ErbB3 ${ }^{K O}$ mammary glands, Interestingly, inhibition of PI3K was unable to modulate STAT5A levels in HC11 cells, and restoration of Akt signaling in ErbB3-depleted HC11 was not sufficient to restore STAT5A expression, despite the previously described ability of Akt to enhance STAT5A stabilization and activity. Because restoration of Akt signaling rescued cell survival but did not rescue STAT5A expression, it is unlikely that selective death of STAT5A-expressing cells is the reason why STAT5A expression is low in the absence of ErbB3. The molecular mechanisms underlying decreased STAT5A expression remain unclear, and will require additional studies. However, we found that ErbB4 upregulation was capable of restoring STAT5A expression in the absence of ErbB3, highlighting the ability of ErbB3 and ErbB4 to compensate for one another. These observations are supported by our findings that the combined loss of both ErbB3 and ErbB4 further impaired Akt and STAT5A signaling in
aMECs (Fig. 5f), thus supporting both cell survival (PI3K to Akt) and lineage commitment/differentiation (STAT5A).

\section{Conclusions}

In summary, we have found that the NRG receptor ErbB3 supports lactogenic expansion of the milk-producing alveolar mammary epithelium during pregnancy, similar to what was found for the only other known NRG receptor, ErbB4. Given the importance of lactation for the survival of mammalian species, it may not be surprising that compensatory signaling mechanisms exist, ones that will ensure adequate lactation even if a single pathway is compromised. The important roles played by the NRG ligands and their two receptors in driving lactogenesis of the mammary epithelium during pregnancy are becoming increasingly evident. Although PRL is a known activator of STAT5 in the mammary gland, these data showing ErbB3-dependent induction of STAT5 expression, taken with previous data demonstrating ErbB4mediated phosphorylation and activation of STAT5, suggest that NRGs produced locally in the mammary microenvironment enable PRL-mediated STAT5A activation, while at the same time promoting PI3K/Akt signaling, which together amplify, sustain, and differentiate this unique cell population on which newborn mammals depend.

\section{Additional file}

Additional file 1: is Figure S1 showing ErbB3 $\mathrm{HC}$ of mammary glands harvested at 16.5 d.p.c. and L1, Figure S2 showing immunofluorescence for ErbB3 and Cytokeratin-8 (K8) in mammary glands harvested at 16.5 d.p.c. Figure S3 showing mammary glands harvested from 12-15-week-old mice at 16.5 d.p.c., L1 and L5, and stained using IHC for Ki67 (representative images, original magnification 400x), Figure S4 showing mammary glands harvested from 12-15-week-old mice at 16.5 d.p.c. and L1, assessed by TUNEL analysis in situ (representative images, original magnification $400 \times)$, Figure S5 showing P-Akt S473 IHC of mammary glands harvested from 12-15-week-old mice at 16.5 d.p.c., L1, and L5, and stained using $I H C$ for P-Akt Serine 473 (representative images, original magnification 400x), Figure S6 showing HC11 cells treated with BKM120 (1 $\mu \mathrm{M})$ or AZD6244 $(1 \mu \mathrm{M})$ for $4 \mathrm{~h}$ : $\mathbf{A}$ western blot analysis using antibodies listed at the left (representative images, repeated three times) and $\mathbf{B}$ cell cultures stained with Annexin V-FITC to detect apoptotic cells, and Annexin $\mathrm{V}^{+}$cells quantitated in digital images (experiments assessed in duplicate and repeated three times; data points are the average of the experimental duplicates; midlines are the average ( \pm SD) of the biological replicates; Student's unpaired $t$ test), Figure $\mathbf{S 7}$ showing immunohistochemical detection of P-STAT5 A/B in mammary glands, Figure S8 showing $\mathrm{HC} 11$ cells expressing shErbB3 or shScr serum and EGF-starved for $24 \mathrm{~h}$ in the presence or absence of NRG1 $\beta(2 \mathrm{ng} / \mathrm{ml})$, then stained with Annexin V-FITC to detect apoptotic cells, and Annexin $\mathrm{V}^{+}$cells quantitated in digital images (experiments assessed in duplicate and repeated three times; data points are the average of the experimental duplicates; midlines are the average ( \pm SD) of the biological replicates; Student's unpaired $t$ test) Figure S9 showing $\mathbf{A} \mathrm{HC} 11$ cells expressing shErbB3 or shScr serum and EGF-starved for $24 \mathrm{~h}$ in the presence or absence of PRL, then whole RNA assessed by RT-qPCR for transcripts encoding ErbB2 and EGFR (experiments assessed in duplicate, repeated three times; data points are the average of the experimental duplicates; midlines are the average $( \pm S D)$ of the 
biological replicates: Student's unpaired $t$ test) and $\mathbf{B}, \mathbf{C} I \mathrm{HC}$ used to visualize ErbB2 expression in mammary glands harvested at 16.5 d.p.c., L1, and $L 5$ from uniparous ErbB3 ${ }^{W T}$ and $E r b B 3^{K O}$ mice (panels in (C) identical to panels in (B), but include a wider field of view), and Figure $\mathbf{S 1 0}$ showing $\mathbf{A}$ HC11 cells expressing shErbB3 or shScr serum and EGF-starved for 30 min in the presence or absence of NRG1 $\beta$ or PRL (whole cell lysates assessed by western blot analysis using the antibodies indicated at the left; $\mathrm{MW}$ molecular weight marker) and $\mathbf{B} \mathrm{HC} 11$ cells expressing shErbB3 or shScr serum and EGF-starved for $48 \mathrm{~h}$ in the presence of PRL, BKM120 (1 $\mu \mathrm{M})$ or BSK805 $(1 \mu \mathrm{M})$, with Annexin V-FITC added to cultures for the final 3 $h$, and the number of Annexin $V^{+}$cells counted (each data point shows the average of samples assessed in duplicate, relative to the average value of the number of Annexin $\mathrm{V}^{+}$cells seen in untreated $\mathrm{HC} 11$-shScr cells; midlines are the average ( \pm SD); $N=3$ ) (PPTX $49017 \mathrm{~kb}$ )

\section{Abbreviations}

aMEC: Alveolar mammary epithelial cell; d.p.c.: Days post coitus; EGFR: Epidermal

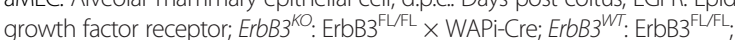
JAK2: Janus kinase 2; L1: Lactation day 1; NRG: Neuregulin; PI3K: Phosphatidyl inositol-3 kinase; PIP3: Phosphoinositol-(3,4,5)-trisphosphate; PRL: Prolactin; RTK: Receptor tyrosine kinase; shErbB3: shRNA sequences against ErbB3; shScr: Scrambled shRNA sequences; STAT5: Signal transduction and activator of transcription

\section{Acknowledgements}

The authors would like to acknowledge Dr Jamie Stanford and Dr Christian Young for their thoughtful discussion of the data. They are grateful for their contributions.

\section{Funding}

This work was supported by Specialized Program of Research Excellence (SPORE) grant NIH P50 CA098131 (VICC), Cancer Center Support grant NIH P30 CA68485 (VICC), NIH F31 CA195989-01 (to MMW), and CTSA UL1TR000445 from the National Center for Advancing Translational Sciences.

\section{Availability of data and materials}

The datasets used and/or analyzed during the current study are available from the corresponding author on reasonable request. Microarray data have been described previously [60] and are publicly available at the National Center for Biotechnology Information Gene Expression Omnibus dataset GDS2843.

\section{Authors' contributions}

MMW performed experiments using HC11 cells. DBV performed animal studies. MMJ generated ErbB3 siRNA and shRNA knockdown in $\mathrm{HC} 11$ cells. DJH performed animal studies. VS performed immunohistochemical analyses of mammary glands. PO performed immunofluorescent analyses of mammary glands. BR assessed and quantitated ErbB3 at lactation day 10 in mammary glands by $\mathrm{HC}$, and assessed ErbB2 in mammary glands harvested at pregnancy day 16.5, lactation day 1, and lactation day 5. DLE cultured HC11-shControl and HC11-shErbB3 cells, harvested RNA, and performed RT-qPCR. JMB performed analyses of expression microarray datasets. RSC designed experiments, interpreted data, and wrote the manuscript. All authors discussed and interpreted data. All authors read the manuscript prior to submission.

\section{Authors' information}

Not applicable.

\section{Ethics approval and consent to participate}

All animal studies were performed in accordance with protocols reviewed and approved by the Vanderbilt University Institutional Animal Care and Use Committee, in AAALAC approved animal care facilities.

\section{Consent for publication}

Not applicable.

\section{Competing interests}

The authors declare that they have no conflicts of interest with the execution or presentation of this research.

\section{Publisher's Note}

Springer Nature remains neutral with regard to jurisdictional claims in published maps and institutional affiliations.

\section{Author details}

'Department of Cancer Biology, Vanderbilt University School of Medicine, 2220 Pierce Avenue, Rm 749 Preston Research Building, Nashville, TN 37232, USA. ${ }^{2}$ Department of Medicine, Vanderbilt University Medical Center, Nashville, TN 37232, USA.

\section{Received: 3 March 2017 Accepted: 7 August 2017}

\section{References}

1. Oftedal OT, Dhouailly D. Evo-devo of the mammary gland. J Mammary Gland Biol Neoplasia. 2013;18(2):105-20.

2. Santoro A, Vlachou T, Carminati M, Pelicci PG, Mapelli M. Molecular mechanisms of asymmetric divisions in mammary stem cells. EMBO Rep. 2016;17(12):1700-20.

3. Asselin-Labat ML, Shackleton M, Stingl J, Vaillant F, Forrest NC, Eaves CJ, Visvader JE, Lindeman GJ. Steroid hormone receptor status of mouse mammary stem cells. J Natl Cancer Inst. 2006;98(14):1011-4.

4. Shackleton M, Vaillant F, Simpson KJ, Stingl J, Smyth GK, Asselin-Labat ML, Wu L, Lindeman GJ, Visvader JE. Generation of a functional mammary gland from a single stem cell. Nature. 2006;439(7072):84-8.

5. Stingl J, Eirew P, Ricketson I, Shackleton M, Vaillant F, Choi D, Li HI, Eaves CJ. Purification and unique properties of mammary epithelial stem cells. Nature. 2006;439(7079):993-7.

6. Villadsen R, Fridriksdottir AJ, Ronnov-Jessen L, Gudjonsson T, Rank F, LaBarge MA, Bissell MJ, Petersen OW. Evidence for a stem cell hierarchy in the adult human breast. J Cell Biol. 2007;177(1):87-101.

7. Shehata M, Teschendorff A, Sharp G, Novcic N, Russell IA, Avril S, Prater M, Eirew P, Caldas C, Watson CJ, et al. Phenotypic and functional characterisation of the luminal cell hierarchy of the mammary gland. Breast Cancer Res. 2012;14(5):R134

8. Wagner KU, Smith GH. Pregnancy and stem cell behavior. J Mammary Gland Biol Neoplasia. 2005:10(1):25-36.

9. Asselin-Labat ML, Vaillant F, Sheridan JM, Pal B, Wu D, Simpson ER, Yasuda H, Smyth GK, Martin TJ, Lindeman GJ, et al. Control of mammary stem cell function by steroid hormone signalling. Nature. 2010;465(7299):798-802.

10. Joshi PA, Jackson HW, Beristain AG, Di Grappa MA, Mote PA, Clarke CL, Stingl J, Waterhouse PD, Khokha R. Progesterone induces adult mammary stem cell expansion. Nature. 2010;465(7299):803-7.

11. Joshi PA, Waterhouse PD, Kannan N, Narala S, Fang H, Di Grappa MA, Jackson HW, Penninger JM, Eaves C, Khokha R. RANK signaling amplifies WNT-responsive mammary progenitors through R-SPONDIN1. Stem Cell Reports. 2015;5(1):31-44.

12. Muraoka-Cook RS, Sandahl M, Hunter D, Miraglia L, Earp 3rd HS. Prolactin and ErbB4/HER4 signaling interact via Janus kinase 2 to induce mammary epithelial cell gene expression differentiation. Mol Endocrinol. 2008;22(10):2307-21.

13. Ormandy CJ, Naylor M, Harris J, Robertson F, Horseman ND, Lindeman GJ, Visvader J, Kelly PA. Investigation of the transcriptional changes underlying functional defects in the mammary glands of prolactin receptor knockout mice. Recent Prog Horm Res. 2003;58:297-323.

14. Hennighausen L, Robinson GW, Wagner KU, Liu W. Prolactin signaling in mammary gland development. J Biol Chem. 1997;272(12):7567-9.

15. Wagner KU, Rui H. Jak2/Stat5 signaling in mammogenesis, breast cancer initiation and progression. J Mammary Gland Biol Neoplasia. 2008;13(1):93-103.

16. Wagner KU, Schmidt JW. The two faces of Janus kinases and their respective STATs in mammary gland development and cancer. J Carcinog. 2011;10:32.

17. Ormandy CJ, Binart N, Kelly PA. Mammary gland development in prolactin receptor knockout mice. J Mammary Gland Biol Neoplasia. 1997;2(4):355-64.

18. Cui Y, Riedlinger G, Miyoshi K, Tang W, Li C, Deng CX, Robinson GW, Hennighausen L. Inactivation of Stat5 in mouse mammary epithelium during pregnancy reveals distinct functions in cell proliferation, survival, and differentiation. Mol Cell Biol. 2004;24(18):8037-47.

19. Liu X, Robinson GW, Wagner KU, Garrett L, Wynshaw-Boris A, Hennighausen L. Stat5a is mandatory for adult mammary gland development and lactogenesis. Genes Dev. 1997;11(2):179-86.

20. Long W, Wagner KU, Lloyd KC, Binart N, Shillingford JM, Hennighausen L, Jones FE. Impaired differentiation and lactational failure of Erbb4-deficient 
mammary glands identify ERBB4 as an obligate mediator of STAT5. Development. 2003;130(21):5257-68.

21. Muraoka-Cook RS, Sandahl M, Husted C, Hunter D, Miraglia L, Feng SM, Elenius K, Earp 3rd HS. The intracellular domain of ErbB4 induces differentiation of mammary epithelial cells. Mol Biol Cell. 2006;17(9):4118-29.

22. Tvorogov D, Sundvall M, Kurppa K, Hollmen M, Repo S, Johnson MS, Elenius K. Somatic mutations of ErbB4: selective loss-of-function phenotype affecting signal transduction pathways in cancer. J Biol Chem. 2009;284(9):5582-91.

23. Forster N, Saladi SV, van Bragt M, Sfondouris ME, Jones FE, Li Z, Ellisen LW. Basal cell signaling by p63 controls luminal progenitor function and lactation via NRG1. Dev Cell. 2014;28(2):147-60.

24. Schulze WX, Deng L, Mann M. Phosphotyrosine interactome of the ErbBreceptor kinase family. Mol Syst Biol. 2005;1:2005.0008.

25. Schroeder JA, Lee DC. Dynamic expression and activation of ERBB receptors in the developing mouse mammary gland. Cell Growth Differ. 1998;9(6):451-64.

26. Jones FE, Welte T, Fu XY, Stern DF. ErbB4 signaling in the mammary gland is required for lobuloalveolar development and Stat5 activation during lactation. J Cell Biol. 1999;147(1):77-88.

27. Tidcombe H, Jackson-Fisher A, Mathers K, Stern DF, Gassmann M, Golding JP. Neural and mammary gland defects in ErbB4 knockout mice genetically rescued from embryonic lethality. Proc Natl Acad Sci U S A. 2003;100(14):8281-6.

28. Muraoka-Cook RS, Sandahl MA, Strunk KE, Miraglia LC, Husted C, Hunter DM, Elenius K, Chodosh LA, Earp 3rd HS. ErbB4 splice variants Cyt1 and Cyt2 differ by 16 amino acids and exert opposing effects on the mammary epithelium in vivo. Mol Cell Biol. 2009;29(18):4935-48.

29. Li L, Cleary S, Mandarano MA, Long W, Birchmeier C, Jones FE. The breast proto-oncogene, HRGalpha regulates epithelial proliferation and lobuloalveolar development in the mouse mammary gland. Oncogene. 2002;21(32):4900-7.

30. Yu WH, Woessner Jr JF, McNeish JD, Stamenkovic I. CD44 anchors the assembly of matrilysin/MMP-7 with heparin-binding epidermal growth factor precursor and ErbB4 and regulates female reproductive organ remodeling. Genes Dev. 2002;16(3):307-23.

31. Jones FE, Jerry DJ, Guarino BC, Andrews GC, Stern DF. Heregulin induces in vivo proliferation and differentiation of mammary epithelium into secretory lobuloalveoli. Cell Growth Differ. 1996;7(8):1031-8.

32. Kennedy SP, Hastings JF, Han JZ, Croucher DR. The under-appreciated promiscuity of the epidermal growth factor receptor family. Front Cell Dev Biol. 2016;4:88

33. Stern DF. ERBB3/HER3 and ERBB2/HER2 duet in mammary development and breast cancer. J Mammary Gland Biol Neoplasia. 2008;13(2):215-23.

34. Guy PM, Platko JV, Cantley LC, Cerione RA, Carraway 3rd KL. Insect cellexpressed p180erbB3 possesses an impaired tyrosine kinase activity. Proc Natl Acad Sci U S A. 1994;91(17):8132-6.

35. Engelman JA, Cantley LC. The role of the ErbB family members in non-small cell lung cancers sensitive to epidermal growth factor receptor kinase inhibitors. Clin Cancer Res. 2006;12(14 Pt 2):4372s-6s.

36. Kobayashi T, Cohen P. Activation of serum- and glucocorticoid-regulated protein kinase by agonists that activate phosphatidylinositide 3-kinase is mediated by 3-phosphoinositide-dependent protein kinase-1 (PDK1) and PDK2. Biochem J. 1999:339(Pt 2):319-28.

37. Sarbassov DD, Guertin DA, Ali SM, Sabatini DM. Phosphorylation and regulation of Akt/PKB by the rictor-mTOR complex. Science. 2005;307(5712): 1098-101.

38. Arteaga $\mathrm{CL}$, Engelman JA. ERBB receptors: from oncogene discovery to basic science to mechanism-based cancer therapeutics. Cancer Cell. 2014;25(3):282-303.

39. Dupont J, Renou JP, Shani M, Hennighausen L, LeRoith D. PTEN overexpression suppresses proliferation and differentiation and enhances apoptosis of the mouse mammary epithelium. J Clin Invest. 2002;110(6):815-25.

40. Maroulakou IG, Oemler W, Naber SP, Klebba I, Kuperwasser C, Tsichlis PN. Distinct roles of the three Akt isoforms in lactogenic differentiation and involution. J Cell Physiol. 2008;217(2):468-77.

41. Chen CC, Boxer RB, Stairs DB, Portocarrero CP, Horton RH, Alvarez JV, Birnbaum MJ, Chodosh LA. Akt is required for Stat5 activation and mammary differentiation. Breast Cancer Res. 2010;12(5):R72.

42. Chen CC, Stairs DB, Boxer RB, Belka GK, Horseman ND, Alvarez JV, Chodosh $L A$. Autocrine prolactin induced by the Pten-Akt pathway is required for lactation initiation and provides a direct link between the Akt and Stat5 pathways. Genes Dev. 2012;26(19):2154-68.
43. Schwertfeger KL, McManaman JL, Palmer CA, Neville MC, Anderson SM. Expression of constitutively activated Akt in the mammary gland leads to excess lipid synthesis during pregnancy and lactation. J Lipid Res. 2003:44(6):1100-12.

44. Moorehead RA, Fata JE, Johnson MB, Khokha R. Inhibition of mammary epithelial apoptosis and sustained phosphorylation of Akt/PKB in MMTV-IGFII transgenic mice. Cell Death Differ. 2001;8(1):16-29.

45. Schwertfeger KL, Richert MM, Anderson SM. Mammary gland involution is delayed by activated Akt in transgenic mice. Mol Endocrinol. 2001;15(6):867-81.

46. Jackson-Fisher AJ, Bellinger G, Breindel JL, Tavassoli FA, Booth CJ, Duong JK, Stern DF. ErbB3 is required for ductal morphogenesis in the mouse mammary gland. Breast Cancer Res. 2008;10(6):R96.

47. Lahlou H, Muller T, Sanguin-Gendreau V, Birchmeier C, Muller WJ. Uncoupling of PI3K from ErbB3 impairs mammary gland development but does not impact on ErbB2-induced mammary tumorigenesis. Cancer Res. 2012;72(12):3080-90.

48. Balko JM, Miller TW, Morrison MM, Hutchinson K, Young C, Rinehart C, Sanchez V, Jee D, Polyak K, Prat A, et al. The receptor tyrosine kinase ErbB3 maintains the balance between luminal and basal breast epithelium. Proc Natl Acad Sci U S A. 2012;109(1):221-6.

49. Wintermantel TM, Mayer AK, Schutz G, Greiner EF. Targeting mammary epithelial cells using a bacterial artificial chromosome. Genesis. 2002;33(3):125-30.

50. Vaught DB, Stanford JC, Young C, Hicks DJ, Wheeler F, Rinehart C, Sanchez V, Koland J, Muller WJ, Arteaga CL, et al. HER3 is required for HER2-induced preneoplastic changes to the breast epithelium and tumor formation. Cancer Res. 2012;72(10):2672-82.

51. Ball RK, Friis RR, Schoenenberger CA, Doppler W, Groner B. Prolactin regulation of beta-casein gene expression and of a cytosolic 120-kd protein in a cloned mouse mammary epithelial cell line. EMBO J. 1988;7(7):2089-95.

52. Lim E, Wu D, Pal B, Bouras T, Asselin-Labat ML, Vaillant F, Yagita $H_{\text {, }}$ Lindeman GJ, Smyth GK, Visvader JE. Transcriptome analyses of mouse and human mammary cell subpopulations reveal multiple conserved genes and pathways. Breast Cancer Res. 2010;12(2):R21.

53. Morrison MM, Hutchinson K, Williams MM, Stanford JC, Balko JM, Young C, Kuba MG, Sanchez V, Williams AJ, Hicks DJ, et al. ErbB3 downregulation enhances luminal breast tumor response to antiestrogens. J Clin Invest. 2013:123(10):4329-43.

54. Miyoshi K, Shillingford JM, Smith GH, Grimm SL, Wagner KU, Oka T, Rosen JM, Robinson GW, Hennighausen L. Signal transducer and activator of transcription (Stat) 5 controls the proliferation and differentiation of mammary alveolar epithelium. J Cell Biol. 2001;155(4):531-42.

55. Durban EM, Medina D, Butel JS. Comparative analysis of casein synthesis during mammary cell differentiation in collagen and mammary gland development in vivo. Dev Biol. 1985:109(2):288-98.

56. Garrett JT, Olivares MG, Rinehart C, Granja-Ingram ND, Sanchez V, Chakrabarty A, Dave B, Cook RS, Pao W, McKinely E, et al. Transcriptional and posttranslational up-regulation of HER3 (ErbB3) compensates for inhibition of the HER2 tyrosine kinase. Proc Natl Acad Sci U S A. 2011:108(12):5021-6.

57. Engelman JA, Janne PA, Mermel C, Pearlberg J, Mukohara T, Fleet C, Cichowski K, Johnson BE, Cantley LC. ErbB-3 mediates phosphoinositide 3-kinase activity in gefitinib-sensitive non-small cell lung cancer cell lines. Proc Natl Acad Sci U S A. 2005;102(10):3788-93.

58. Jones FE, Stern DF. Expression of dominant-negative ErbB2 in the mammary gland of transgenic mice reveals a role in lobuloalveolar development and lactation. Oncogene. 1999;18(23):3481-90.

59. Luetteke NC, Qiu TH, Fenton SE, Troyer KL, Riedel RF, Chang A, Lee DC. Targeted inactivation of the EGF and amphiregulin genes reveals distinct roles for EGF receptor ligands in mouse mammary gland development. Development. 1999:126(12):2739-50.

60. Anderson SM, Rudolph MC, McManaman JL, Neville MC. Key stages in mammary gland development. Secretory activation in the mammary gland: it's not just about milk protein synthesis! Breast Cancer Res. 2007;9(1):204. 